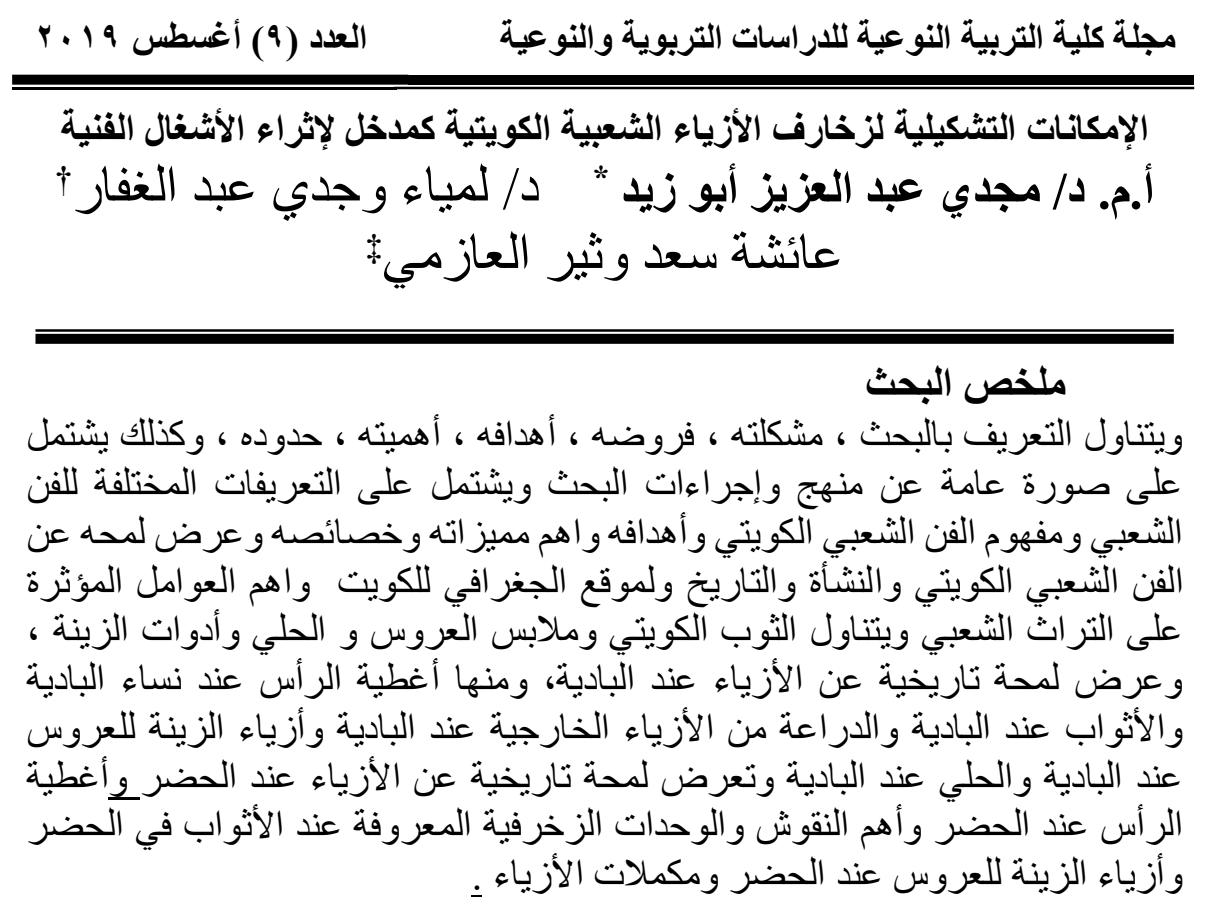

The artistic potential of the popular Kuwaiti folk costume as an entrance to enrich the works of art

Abstract

It also includes a general picture of the research methodology and procedures. It includes the different definitions of popular art, the concept of Kuwaiti folk art, its objectives, its most important features and characteristics, and its presentation on the popular Kuwaiti art, origin, history, geographical location of Kuwait and the most important factors. Which deals with the Kuwaiti dress, the bride's clothes, ornaments and ornaments, and a historical overview of the fashion of the Badia, including the headdresses of the Badia women, the dresses in the desert and the fashions of the foreign costumes at

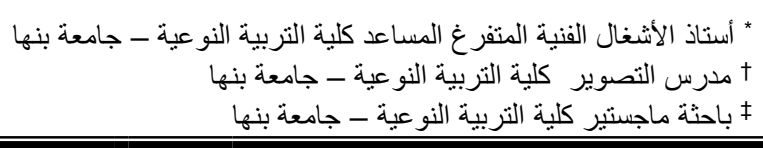




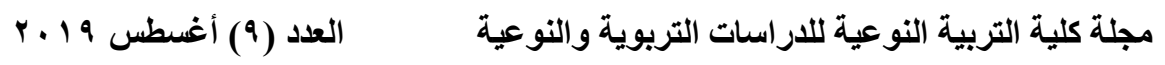

the Badia and When will the desert ornaments when the desert presents a historical overview of fashion when urban and headwear when urban areas and the most important decorative inscriptions and units known when the dresses in urban fashion adornment for the bride when urban and fashion supplements.

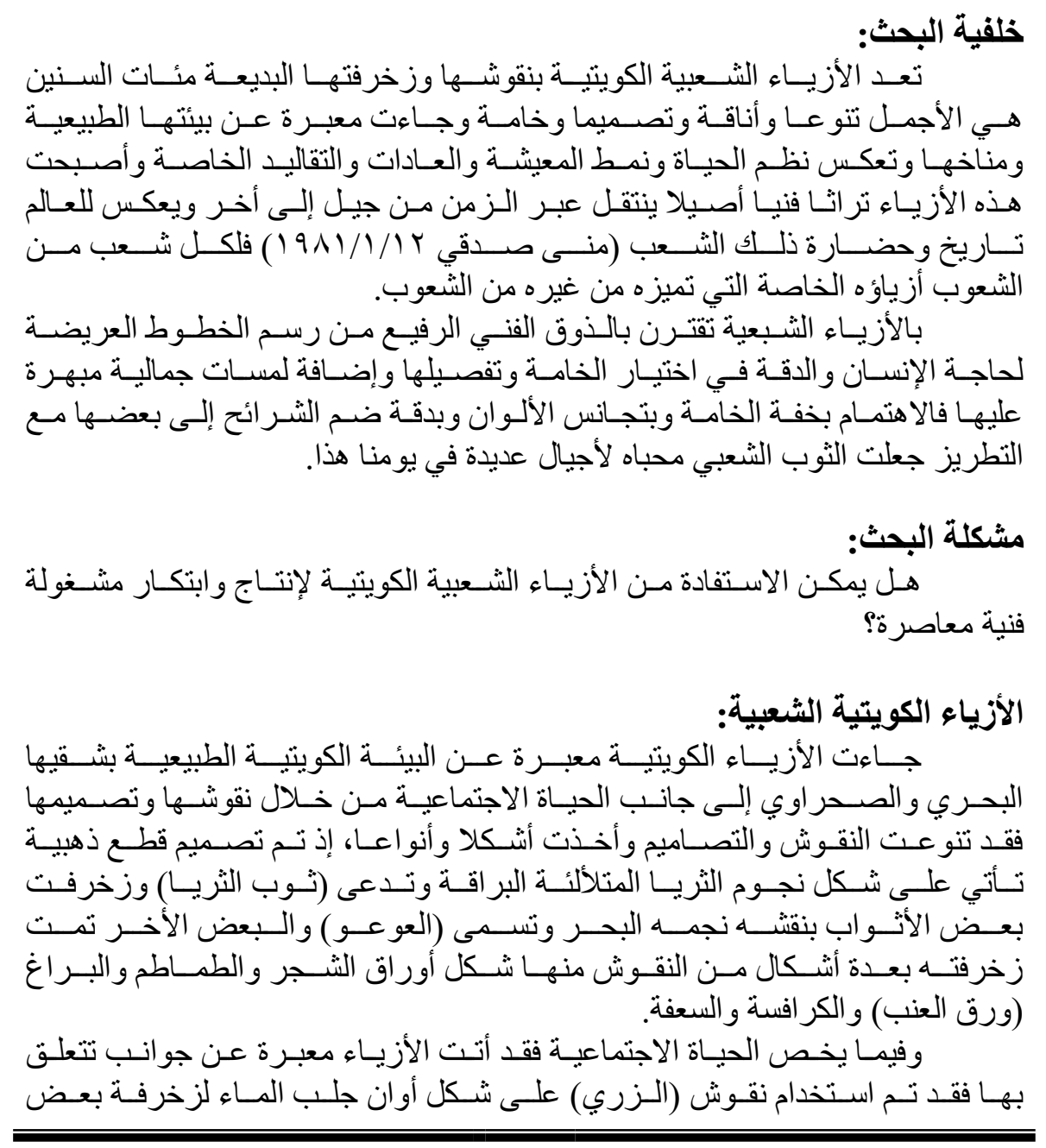




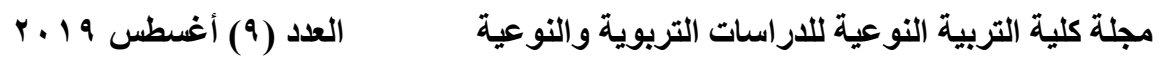

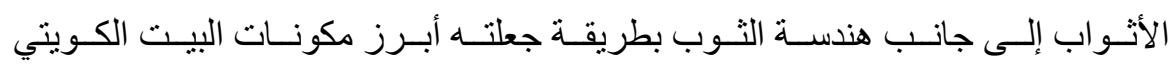

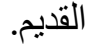

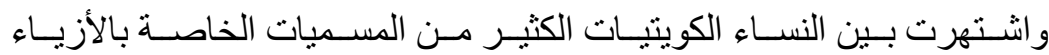

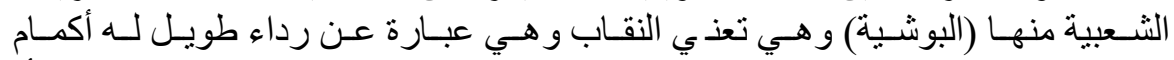

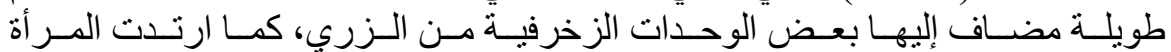

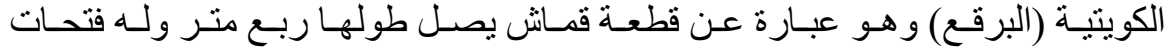

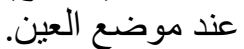

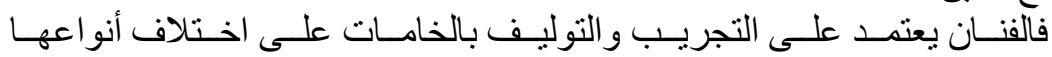

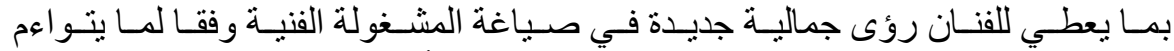

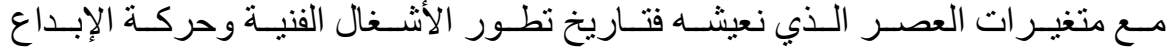

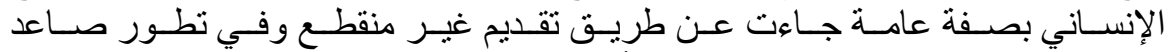

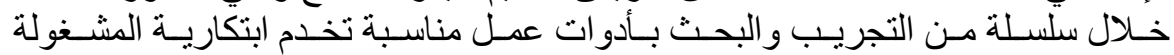

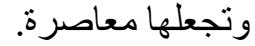

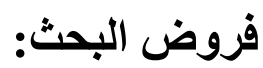
يفترض البحث: - ن البرون

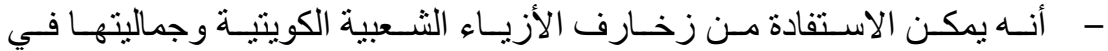
انتاج و ابتكار مشغولة فنية معاصرة.

\section{أهداف الفن الثعبي:}

وللفن الثعبي أهدافه التي يسعى التي: إلى تحقيقها ومنها: ( (1).

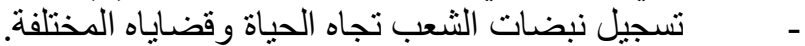

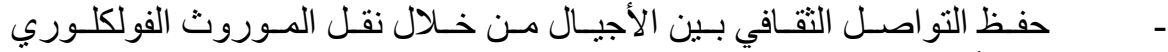
بما يحويه من أبعاد. الوقوف على المدلو لات الفلسفية الكامنة ور اء الرمز و الثكل.

$$
\text { قر اعة لغة الشعوب الحقيقية. }
$$
- - متوثيق الجذور الثقافية و الثعبية.

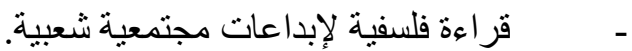

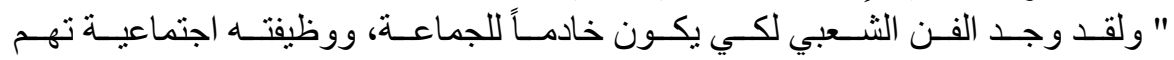

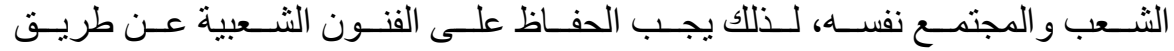

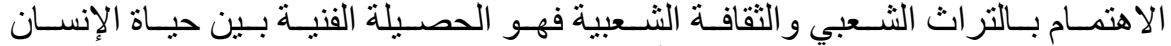

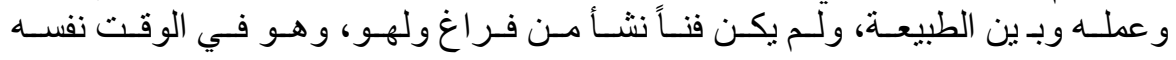




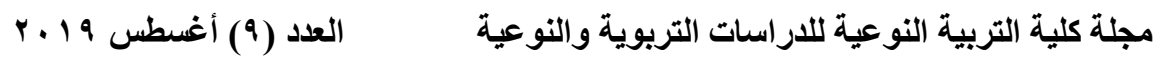

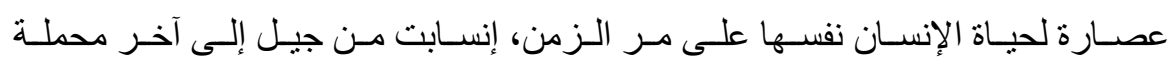

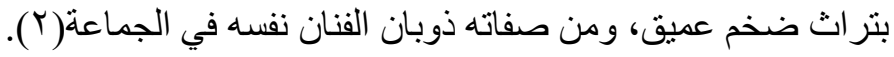

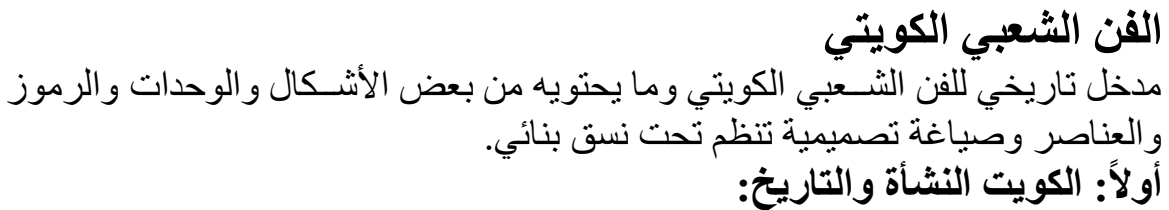

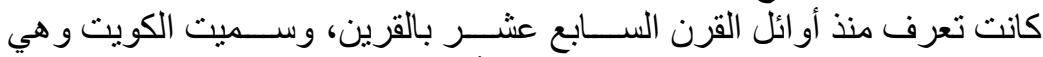

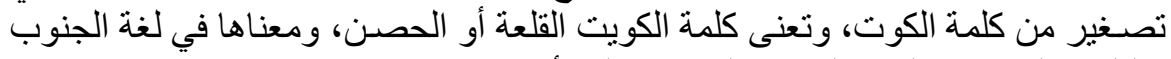
و البلدان المجاورة البيت المبني على هيئة قلعة أو حصن التهن.

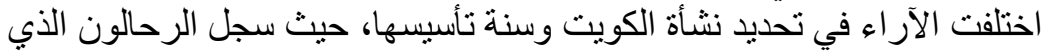

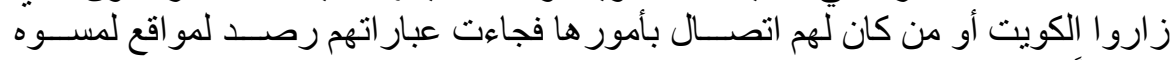

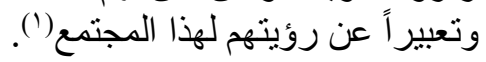

$$
\text { الموقع الجغرافي للكويت:- }
$$

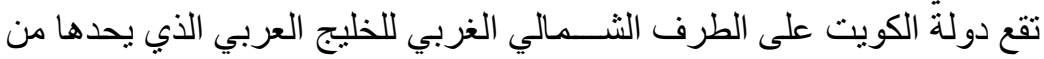

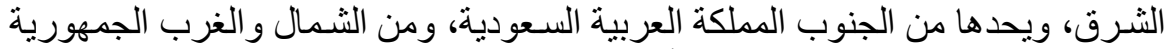

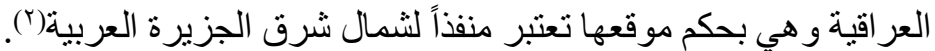

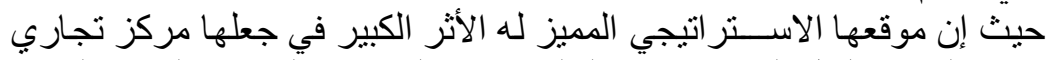

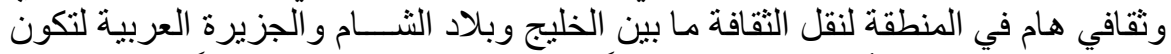

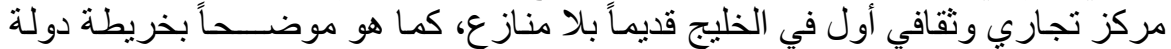

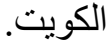

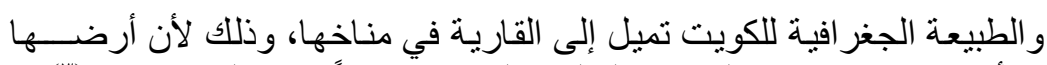

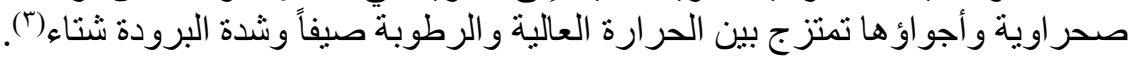

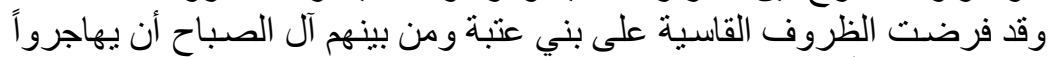

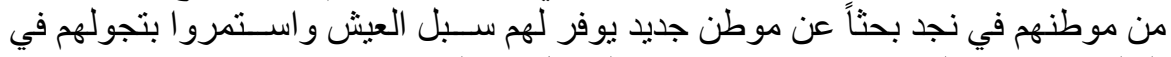

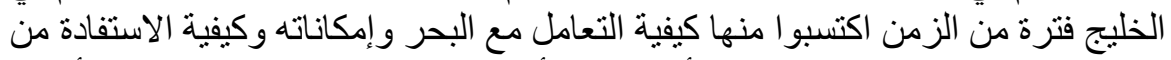

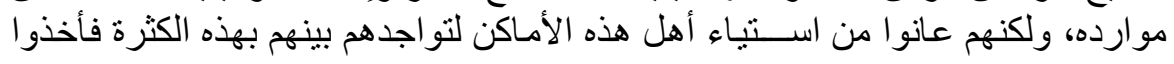

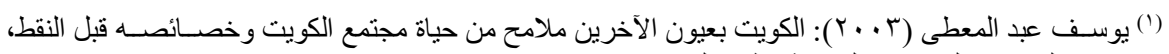

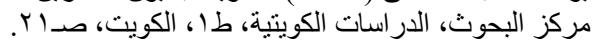

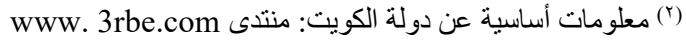

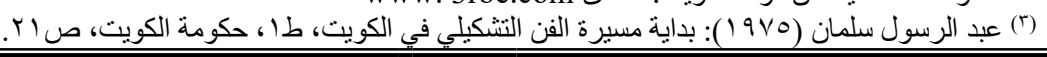




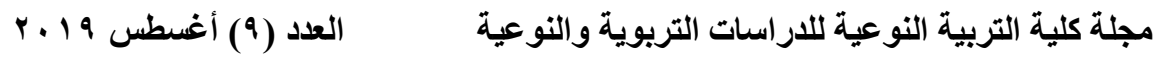

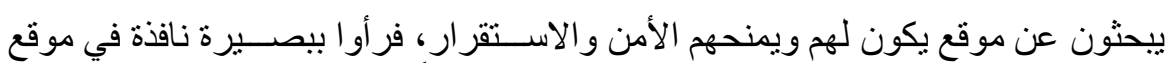

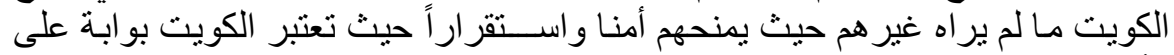

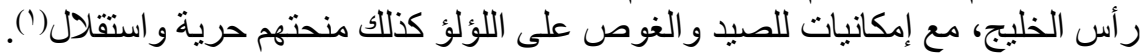

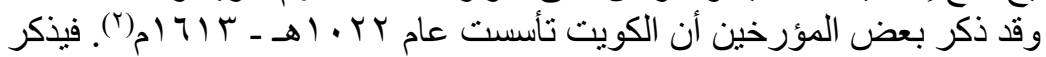

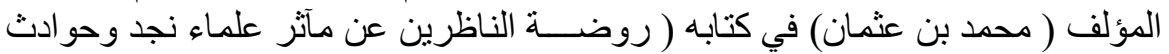

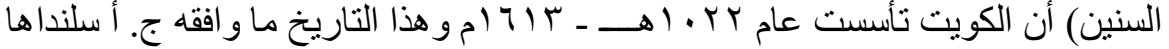
في كتابه التاريخ السياسي للكويت.

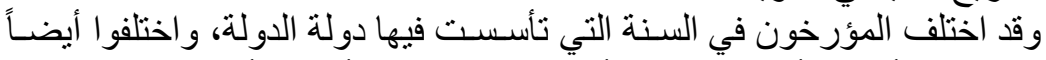

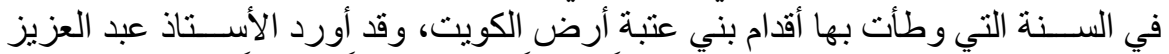

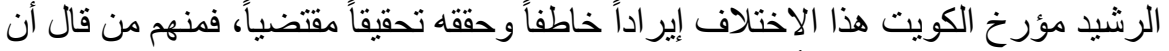

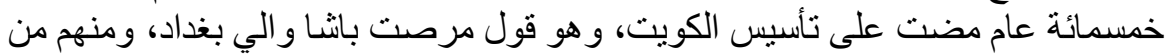

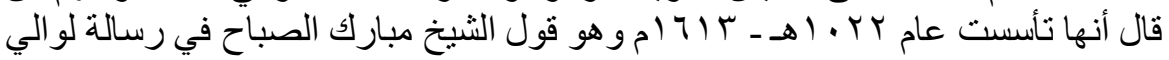

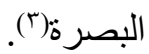

- دراسة وتحليل الأزياء الثعبية الكويتية وما تتميز به وحدات زخرفية.

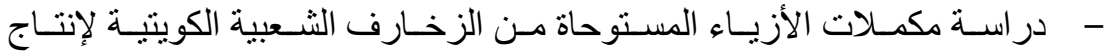
مشغولة فنية مبتكرة معاصرة.

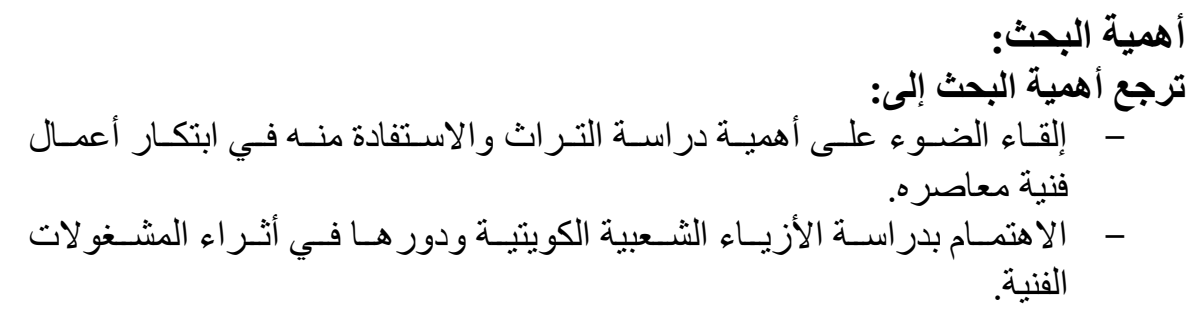
حدود البحث:

( (1) يوسف عبد المعطى (r . . r): الكويت بعيون الآخرين ملامح من حياة مجتمع الكويت وخصسائصسه قبل النقط،

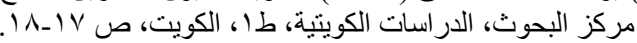

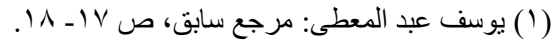

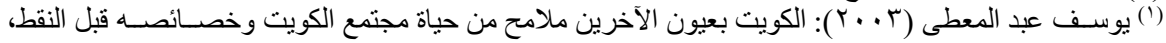

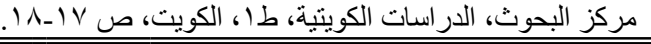




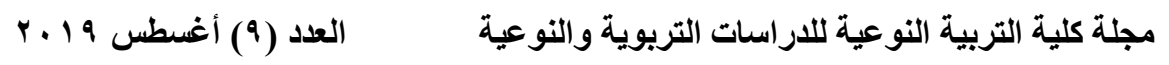

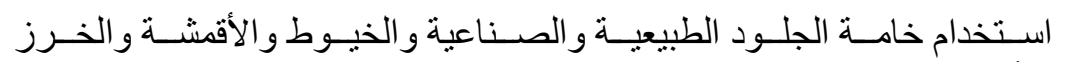
بأنو اعه و الأسلاك المعدنية و الجوخ و الخيش .

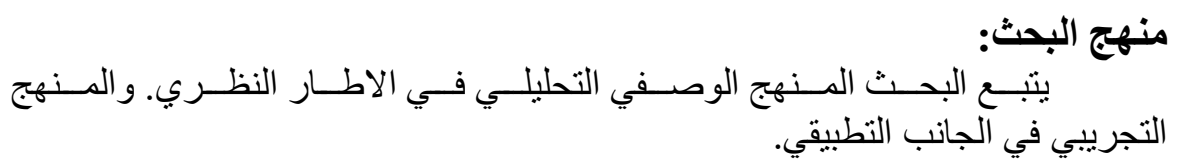
مفهوم الفن الشعبي الكويتي:-

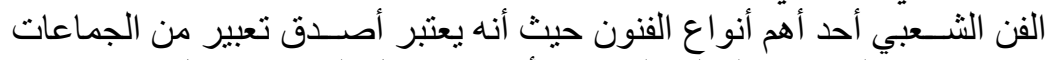

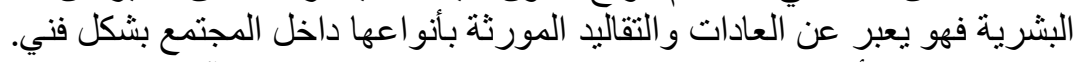

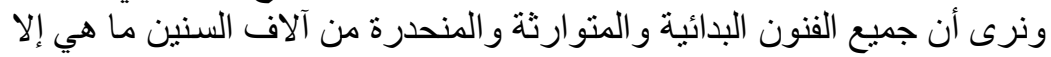

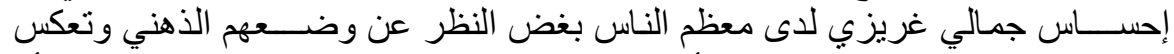

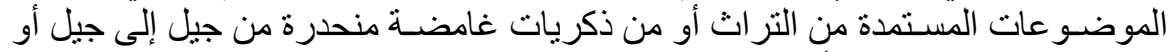

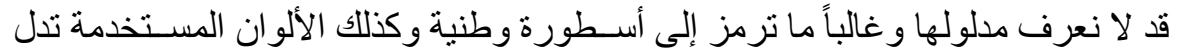

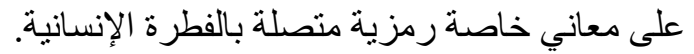

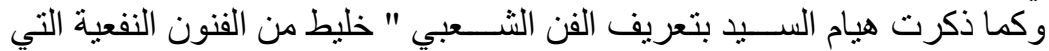

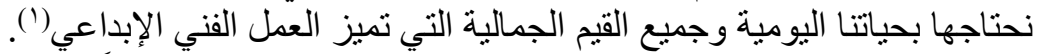

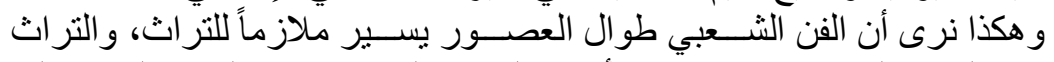

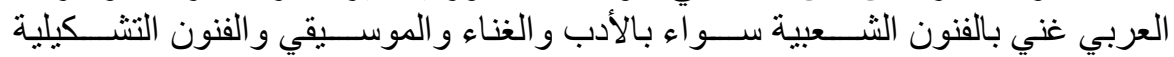
و الزخرفية وهي موضو عات وأثكال مستمدة من التراث الثاء تسلسلت عبر السنوات من جيل

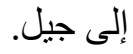

ثانياً: خصائص الفن الشعبي:

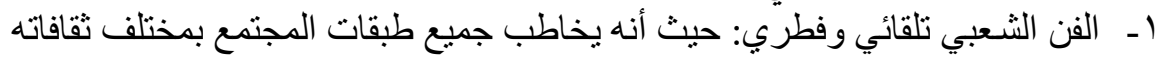

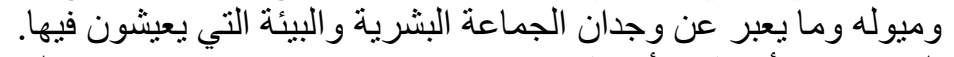

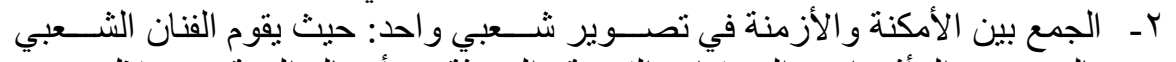

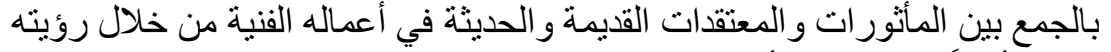

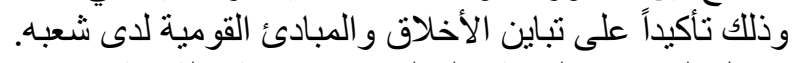

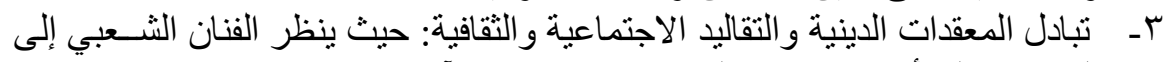
المجتمع على أنه وحدة متكاملة لا يفرق بين فرد المن وآخر.

(') جريدة كل العراق، خصائص وجمالية الفن الشعبيwww Kululiraq .com 


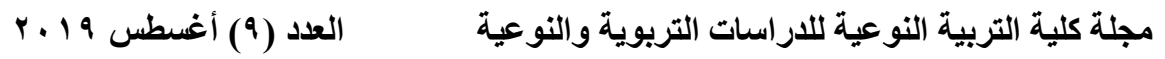

ع ـ تحويل المناطق الجرداء إلى مناطق غناء: حيث اتخذ الفنان رموزه و ألو انه من تلكي

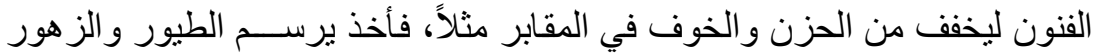

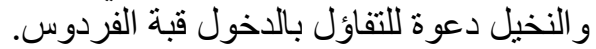

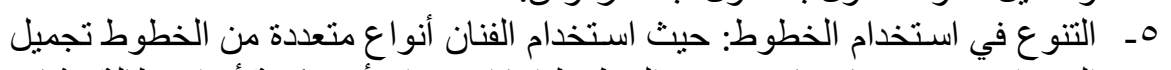

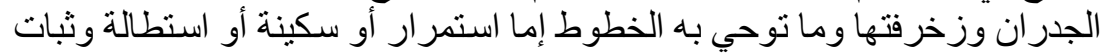

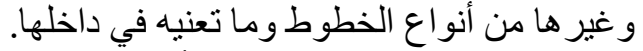

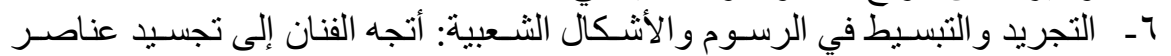

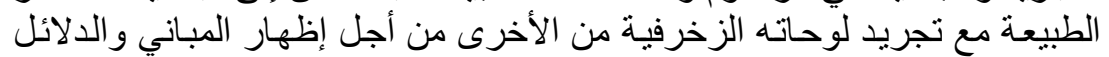
متحرر اً من قيود المادة.

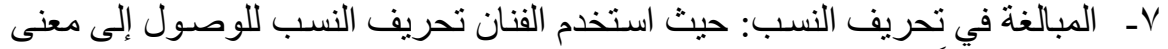

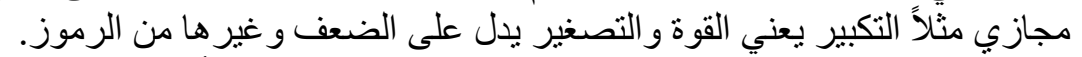

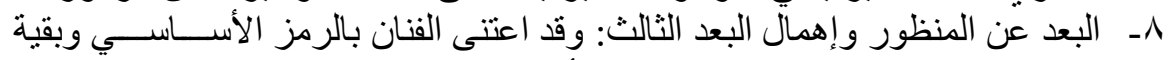
اللوحة تخدم ذللك الرمز دون الإهال الهتمام بالأبعاد.

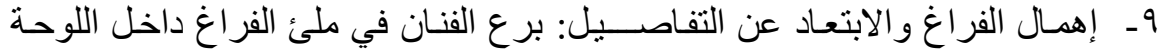
بالألو ان و الخطوط المتعددة لاعتقاده أن الفراغ سكينة الثنيطان.

\section{الأزياء الثعبية الكويتية عند الحضر والبادية}

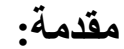

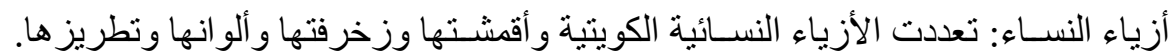

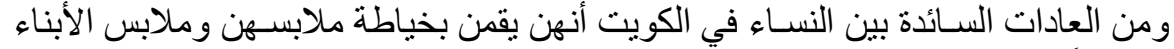

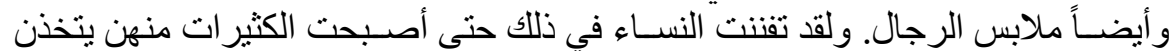

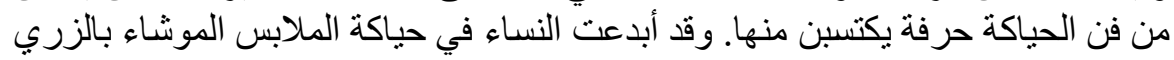

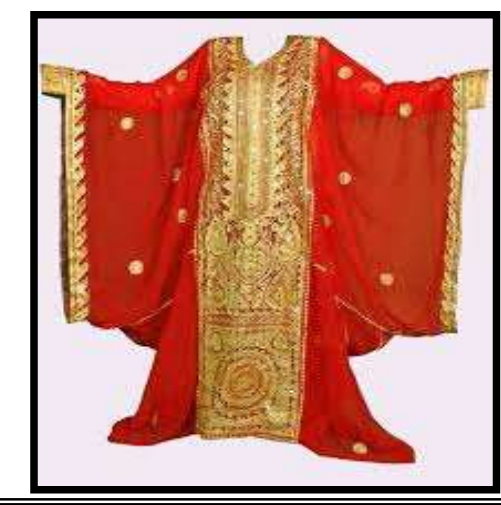

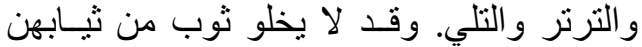

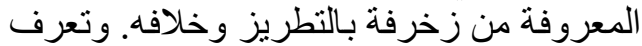

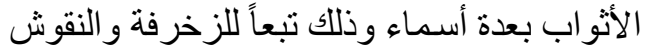

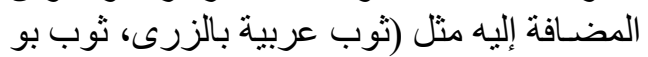

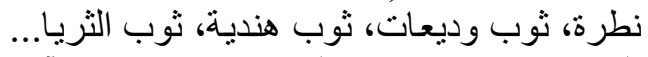

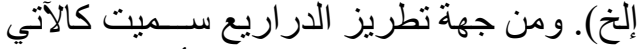

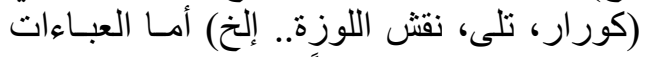

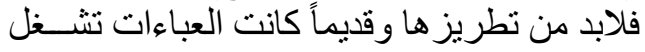

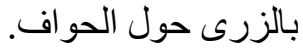




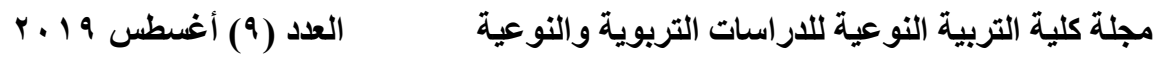

الثوب الكويتي: يعتبر الثوب الكويتي نمطا من أنماط الفنون الثعبية حيث

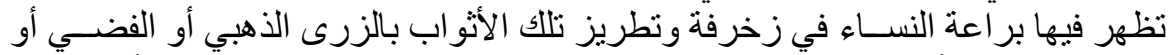

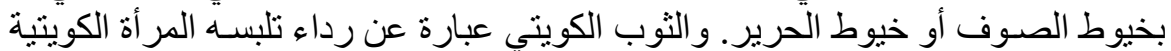

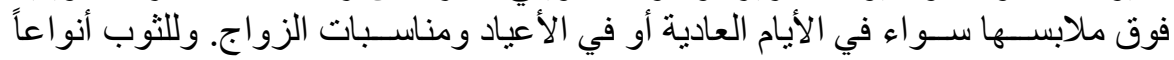

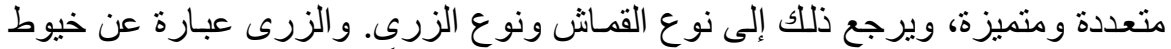

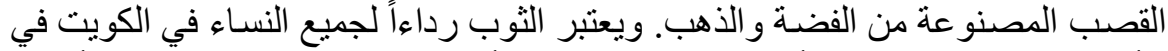

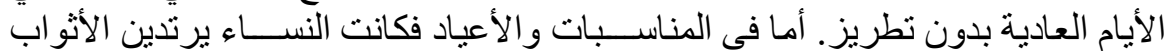

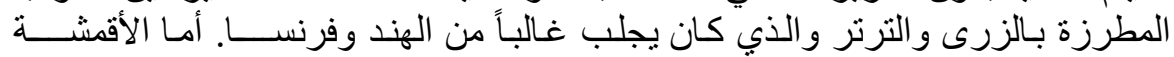

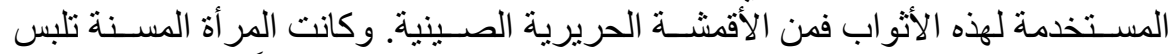

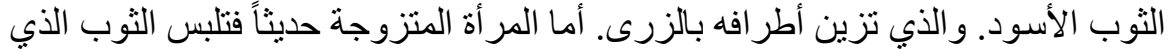

يزخرف بالزرى و الترنز (')

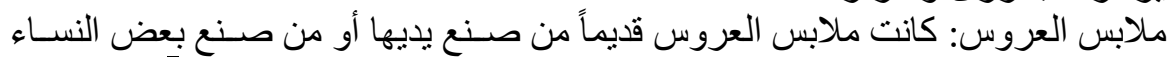

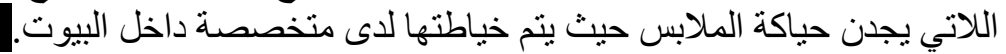

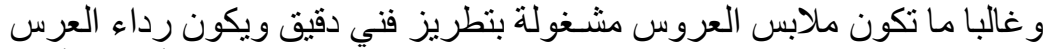

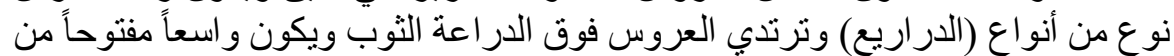

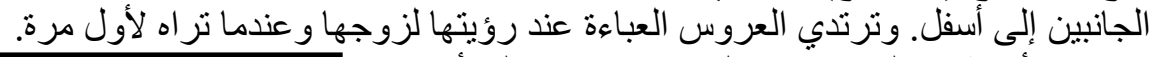

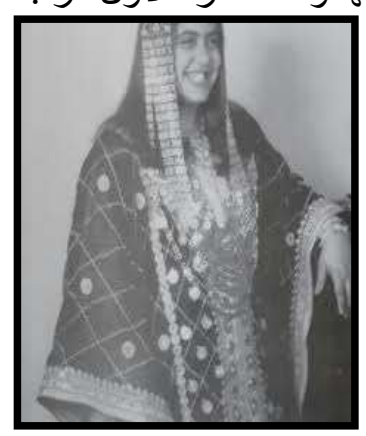

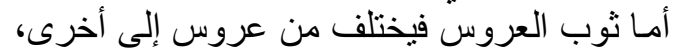

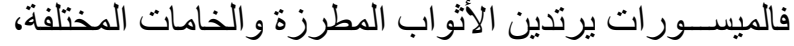

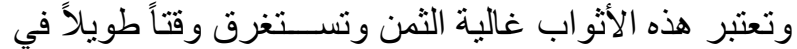

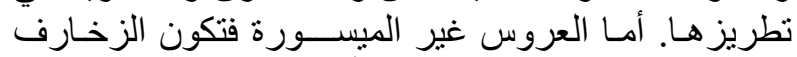

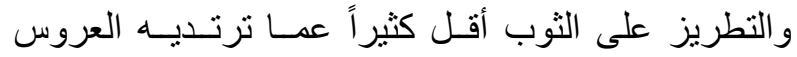
الميسورة. - التطريز

\section{الأزياء عند البادية أغطية الرأس عند نساء البادية علة البادية}




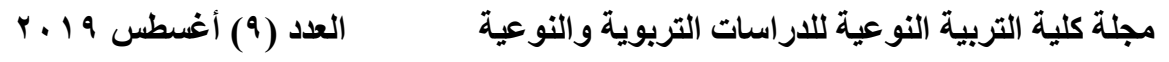

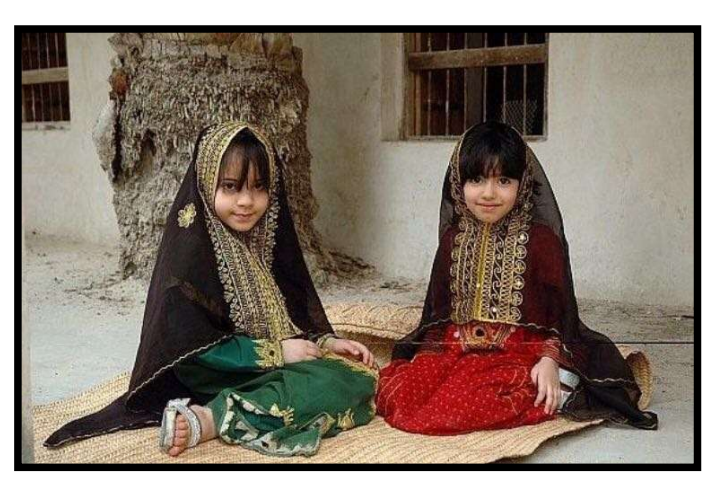

الملفع:-

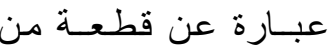

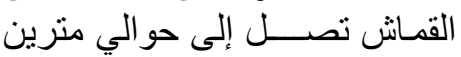

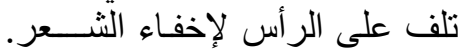

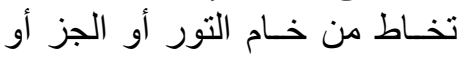

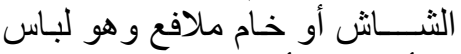

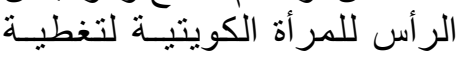

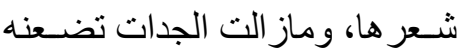

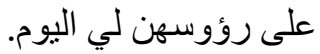

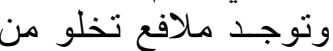

الزخرفة أو أبي تطريز ونوجد ملافع مزخرفة بالتبل ملى ملى أشكال متنو عة بشكل بسيط. البرقع:-

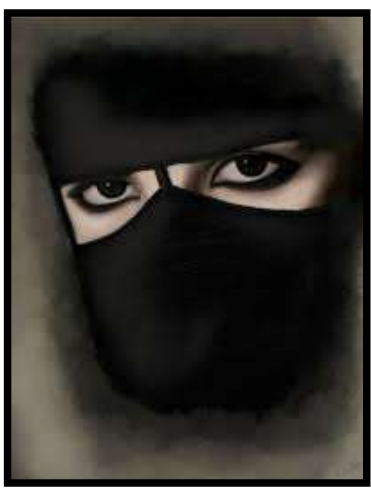

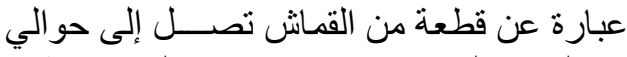

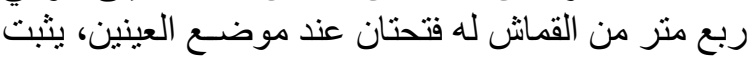

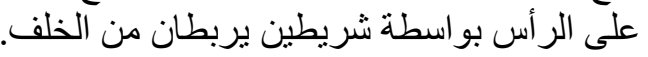

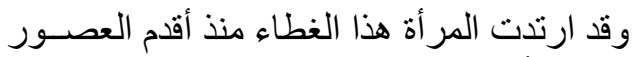

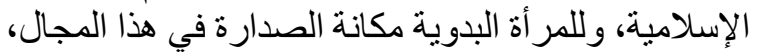

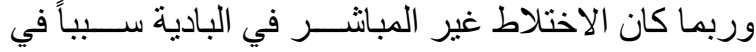

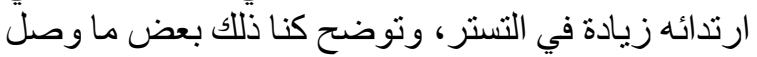

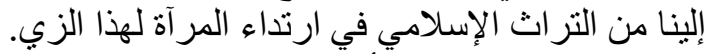

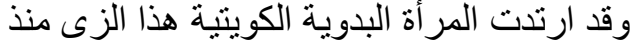

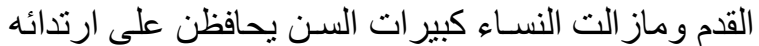

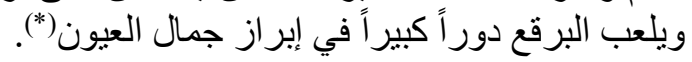

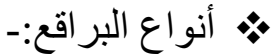
برقع شاش - برقع دبك - برقع مرضوف - برقع جز اوي - برقع شيلة.

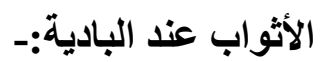




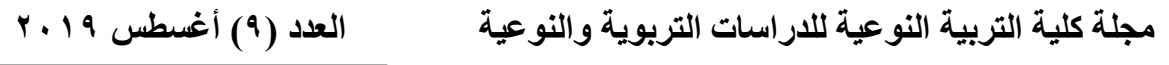

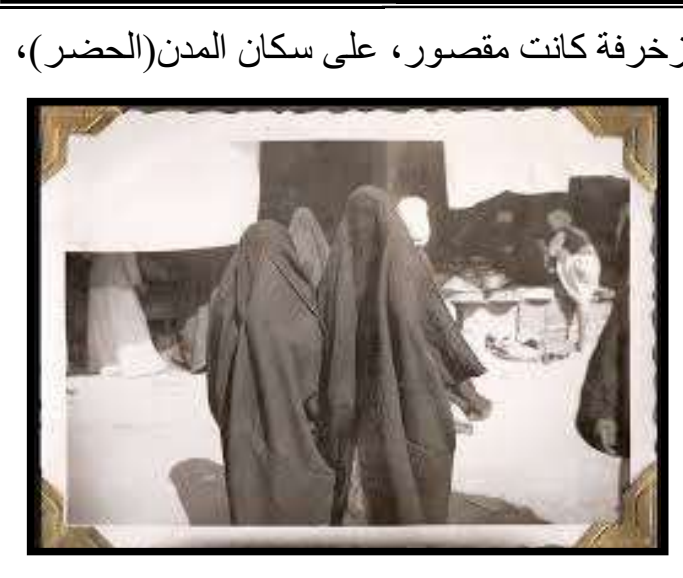

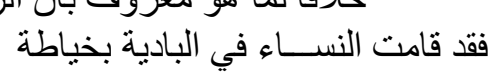

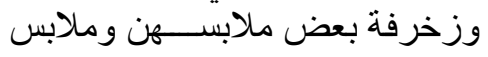

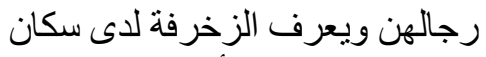

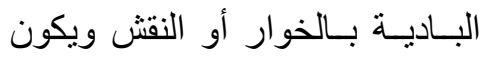

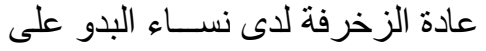

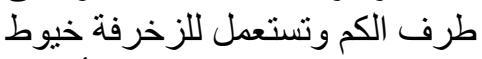

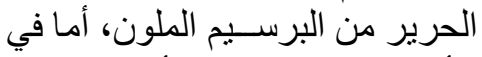

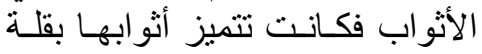
زخرفتها وبساطة زخرفتها.

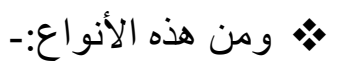

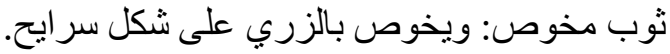

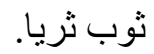

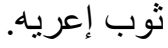
توب بوب بوزيب.

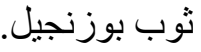

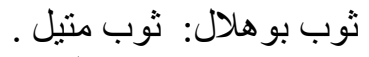

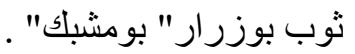

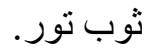
ثوب جز : ثوب نوب امعرمش.

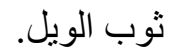

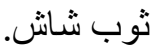
جدول الزخارف

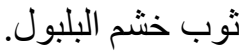

$$
\text { (رسومات و أنشكال الزخارف الزخارف التوضيحية) }
$$

جدول مقارنة الزخارف الثعبية عند البيئة الصحر اوية (البية (البادية)

\begin{tabular}{|c|c|}
\hline البادية & الحضر \\
\hline
\end{tabular}




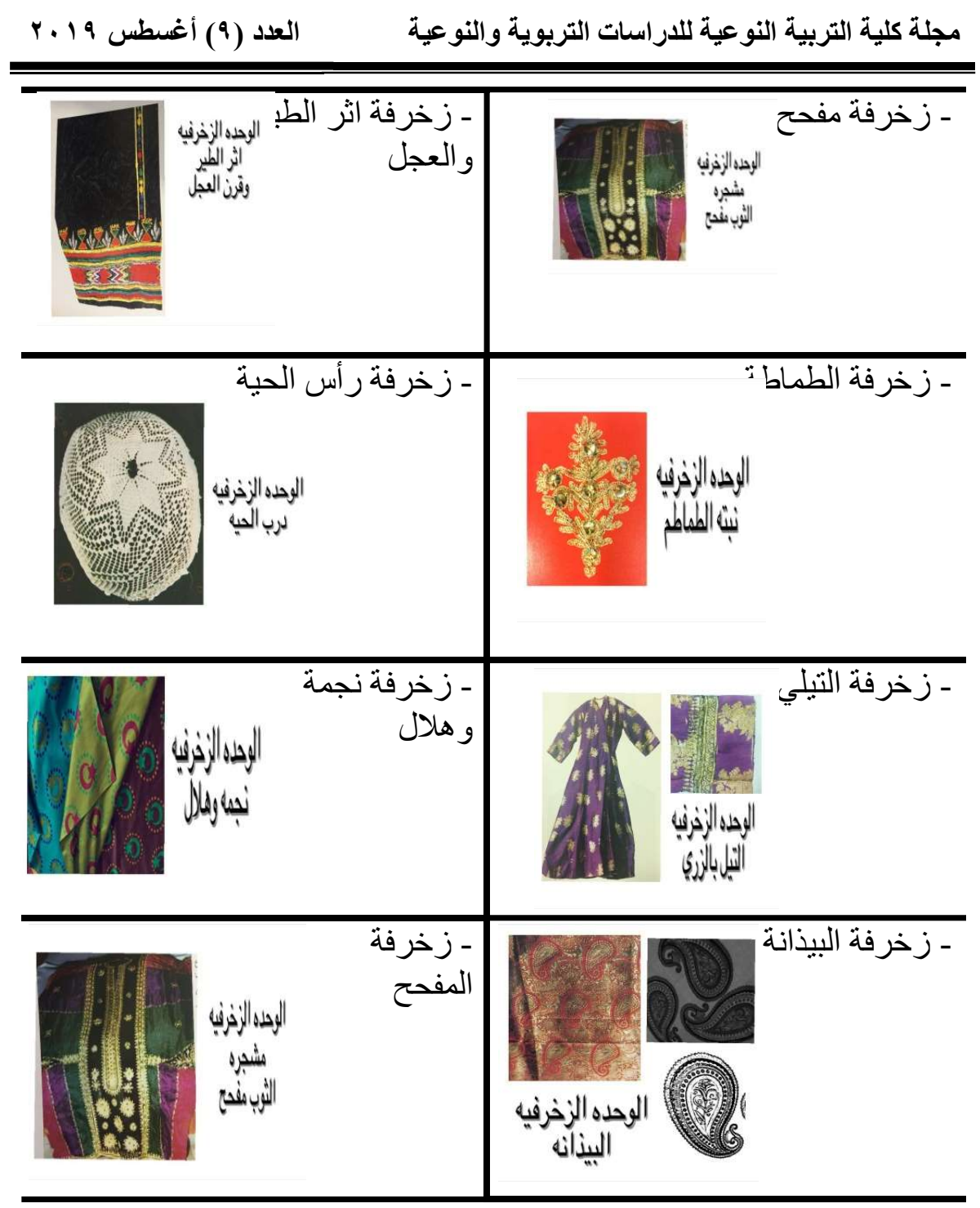




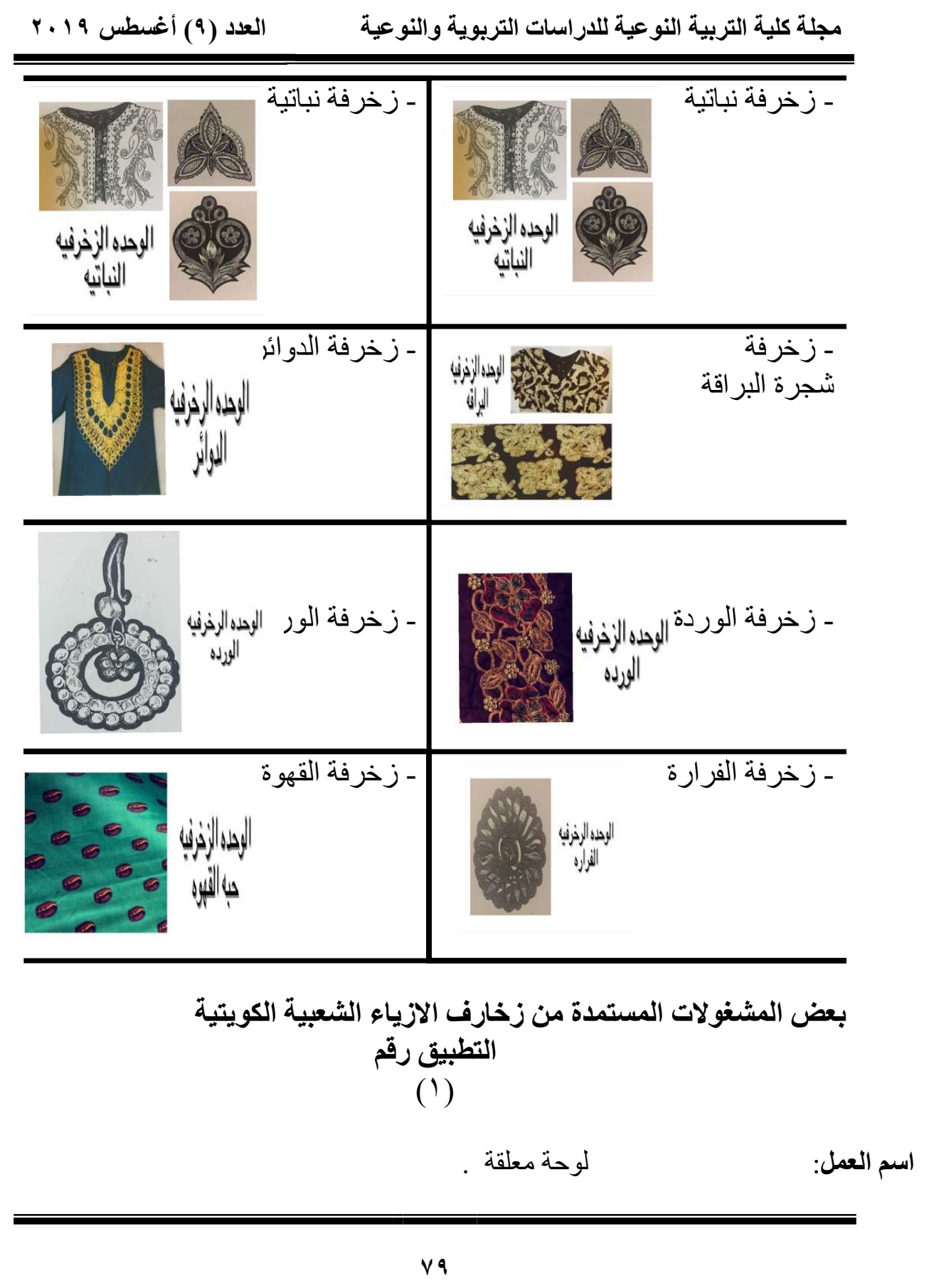




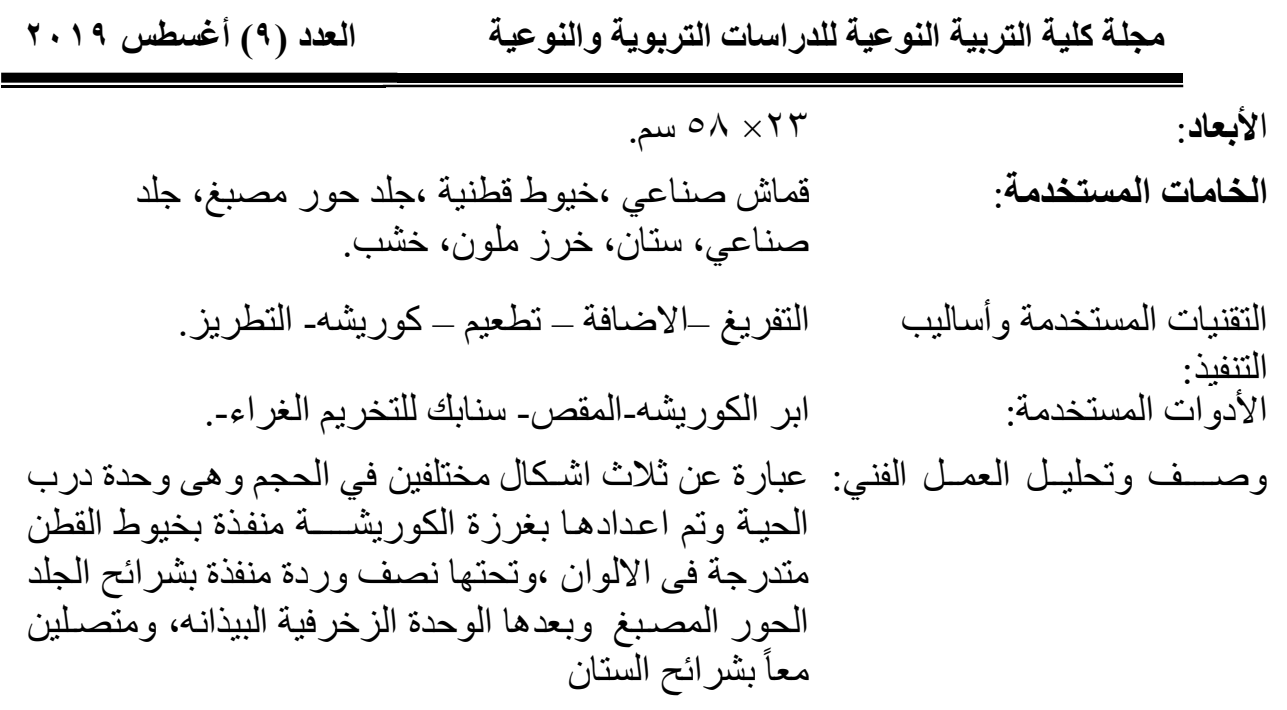




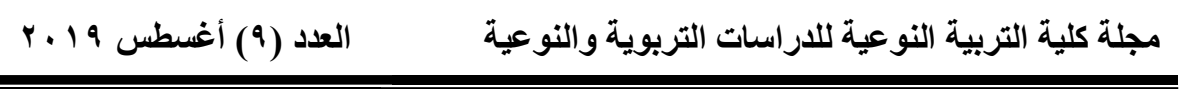

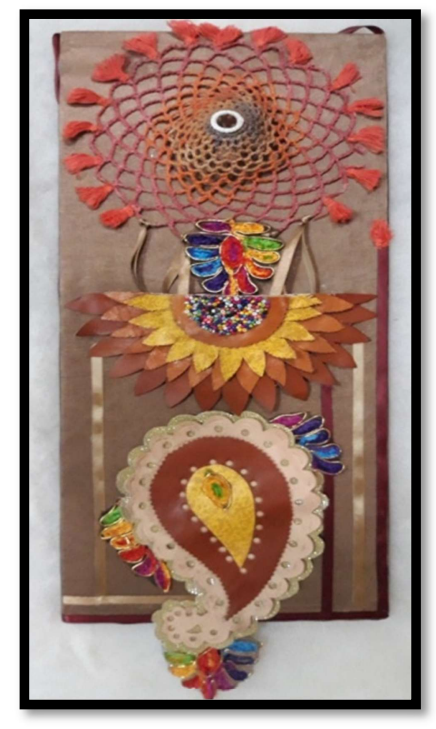

تطبيق رقم (1) - (1)

تطبيق رقم (r) (ب)

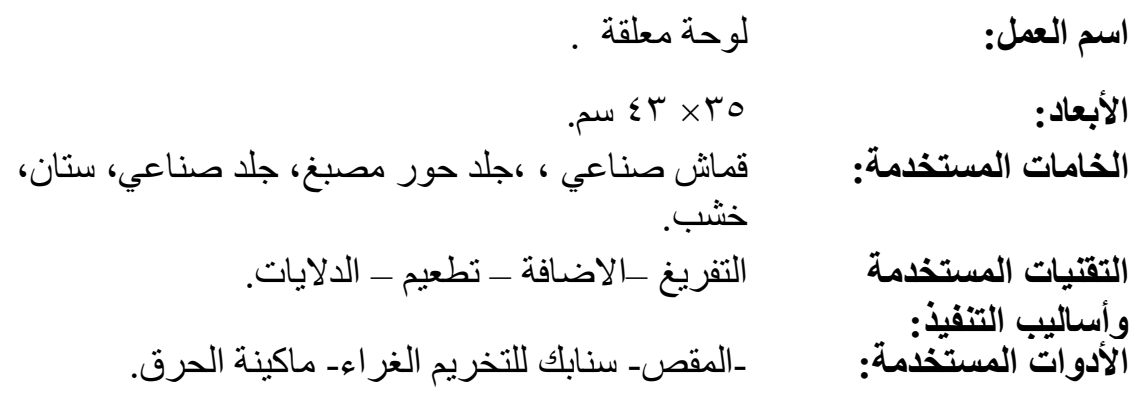




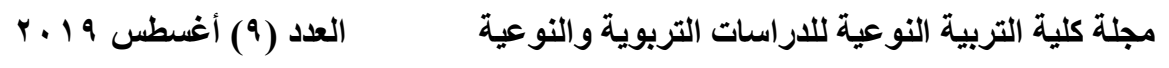

\begin{tabular}{|c|c|}
\hline 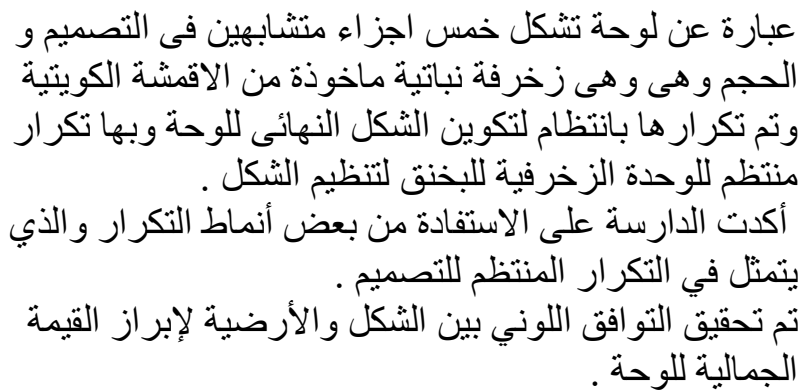 & ولقفي: وتحليل العمل \\
\hline
\end{tabular}

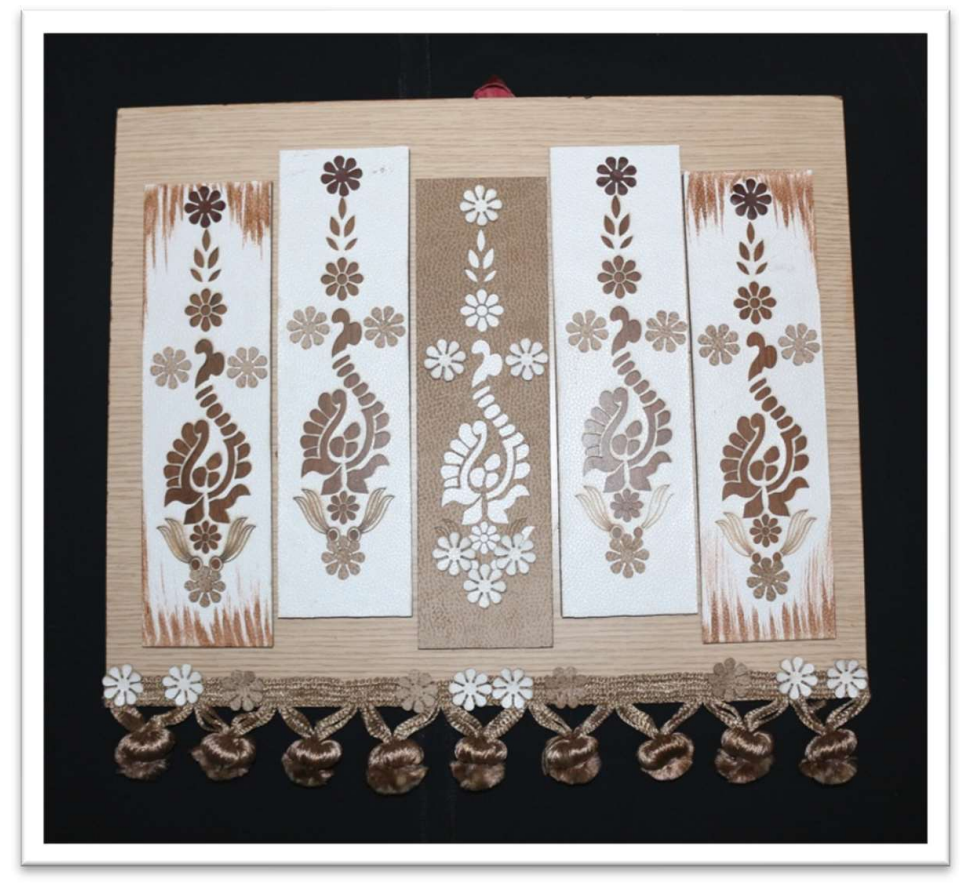

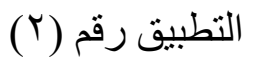




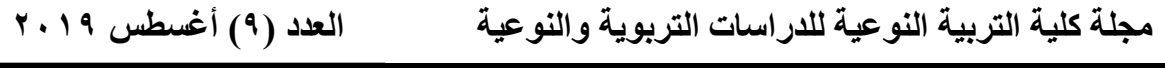

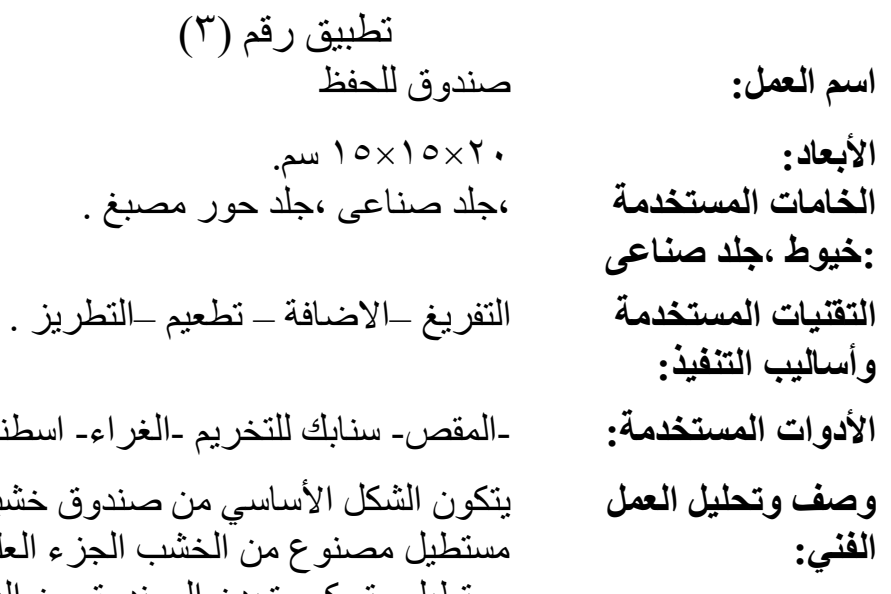

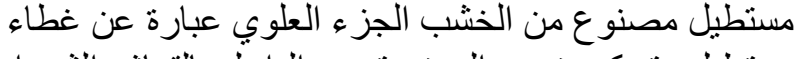

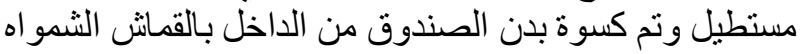

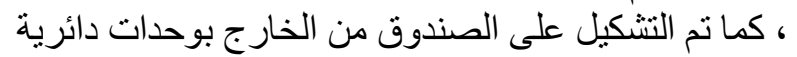

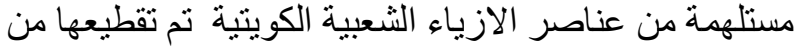
أما جانب الصندوق فتم التشكيل عليه بعمل دو ائر مختلفة

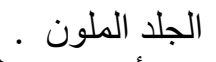

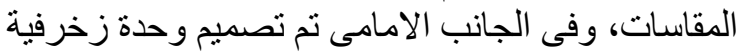
نباتية باسلوب التطريز بالخيوط ـ تعتمد الصياغة الثكلية الأساسية على الاستفادة من العناصر الهندسية والتية النباتية

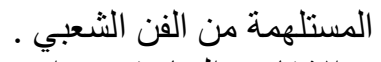

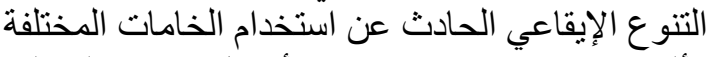

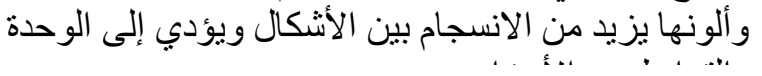




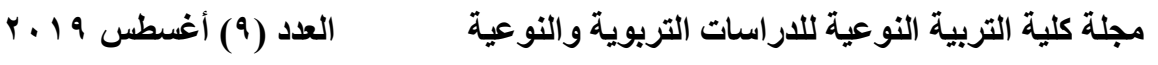

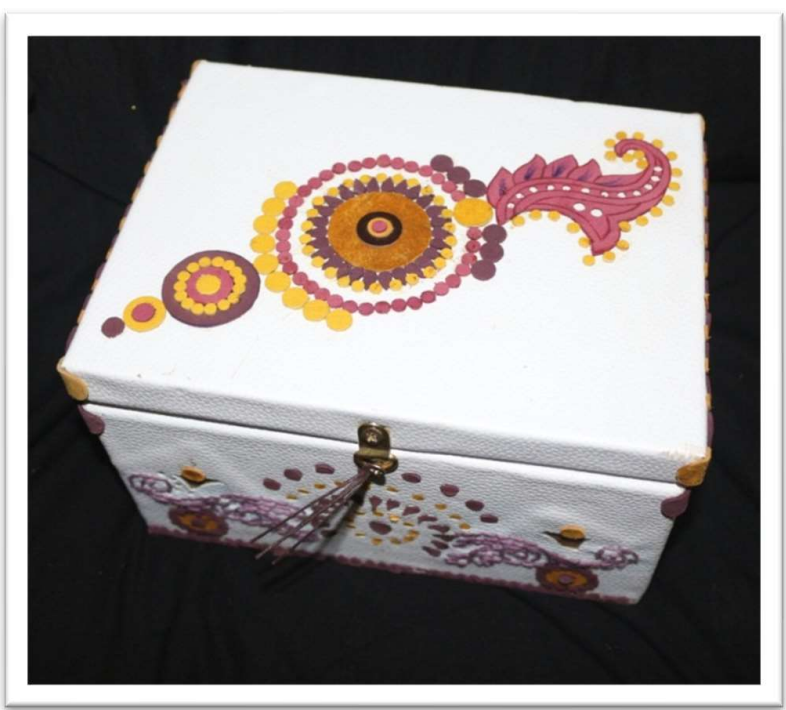

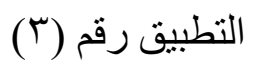

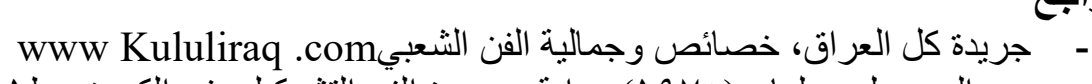

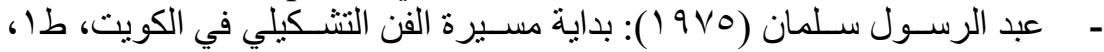

$$
\text { حكومة الكويت. }
$$

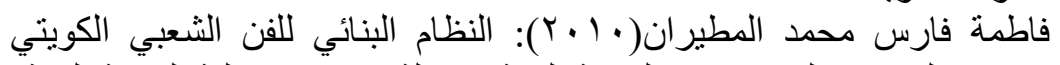
كمصدر لتدريس التصميم في التربية الفنية، رسالة ماجستير، كلية التربية الفنية،

جامعة حلوان.

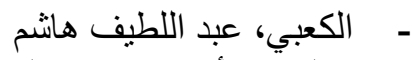

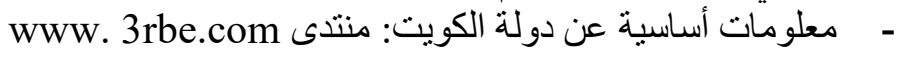

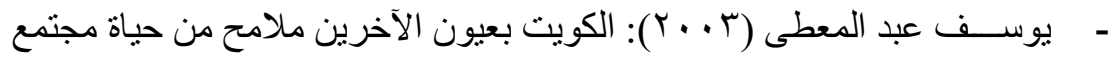

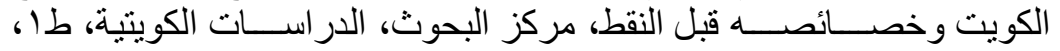

$$
\text { الكويت. }
$$

